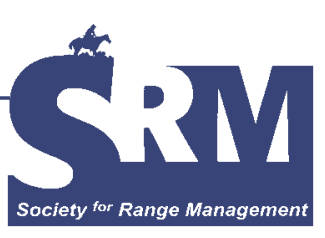

\title{
Readers of Rangelands Survey Results
}

\section{By Gary Frasier}

$\mathrm{I}$ n May and June 2006, a survey (see sidebar table) was sent to the Society for Range Management readers of Rangelands to gain an assessment of how Rangelands as being perceived. The survey was conducted by the Rangelands publishing service, Alliance Communications Group, Allen Press Inc. Over 3,000 surveys were sent via e-mail and 500 copies via Member Resource Nerws. A total of 847 responses were returned through the online version of the survey and 24 paper copies for an overall $26 \%$ response rate.

\section{Demography by Profession}

The demography by profession or work setting as reported by the respondents was compared to the SRM membership by profession reported in the article by Sam Albrecht in the June 2003 issue of Rangelands.

\section{Survey Membership Respondents (2002)}

(\%) (\%)

Federal agency

State/provincial/tribal

36

Rancher

Retired

University researcher/professor 21

University student

Consultant/private

Other

7

5

6

6

14

5
33

6

11

16

16

5

9

4

This comparison shows the respondents were a reasonably good cross section of the SRM membership with only the

This article has been peer reviewed.

rancher and retired members a possible lower representation in the survey.

\section{Question 1. Types of Articles Being Read}

(\% of 871 respondents)

$\begin{array}{ll}\text { Feature } & 98 \\ \text { Technology } & 94 \\ \text { Viewpoints } & 90 \\ \text { Listening to the Land } & 79 \\ \text { Browsing the Literature } & 76 \\ \text { Ask the Expert } & 72 \\ \text { Section News } & 71 \\ \text { Letters to the Editor } & 70 \\ \text { Book Reviews } & 67 \\ \text { REM Highlights } & 61 \\ \text { Charter Members } & 56 \\ \text { Frasier's Philosophy } & 54 \\ \text { Youth Forum } & 52 \\ \text { Poetry } & 39 \\ \text { Recipes } & 37\end{array}$

\section{Question 2}

Each respondent could list up to 3 issues of concern or interest that they would like to have covered in Rangelands. Over 1,800 separate items were listed on the returns. The most frequently mentioned issue was grazing (11\%) followed by ecology (7\%) and success stories/case studies (7\%). These were followed by drought/water/climate (6\%), invasive/noxious weeds (5\%), livestock (4\%) and wildlife (4\%). Other topics 
1. The following columns appear regularly in Rangelands. Please check "I read the column" or "I never read the column."

Ask the Expert
Book Reviews
Browsing the Literature
Charter Member Insights
Feature Articles
Frasier's Philosophy
Highlights of REM
Letters to the Editor
Listening to the Land
Poetry
Recipe Corner
Section News
Viewpoints
Youth Forum
Technology/Methods

2. Please list the top 3 issues of concern or interest you would like to have covered in Rangelands.

3. What types of articles would you be most interested in (check all that apply)?

Profiles (e.g., SRM members, personalities, youth forum)

SRM News (meeting reports, etc.)

How-to (e.g., control burns, manage invasive plants, manage a ranch/finances)

Lifestyle (e.g., personal stories, history, ranch/rangeland culture)

Multicultural (e.g., international range issues, Native American lands)

Government/Association (e.g., BLM lands, legislation, lobbying)

Research (scientific findings)

Opinions/Editorial/Essays

4. The scope of Rangelands is to provide a forum for presenting and discussing facts, ideas, and philosophies pertaining to the study, management, and use of rangelands. Rangelands is nontechnical and provides readers with scientifically correct information in a user-friendly format. Please let us know if you think the scope should change.
I think the scope is fine.

I think the scope should be BROADER by adding the following:

I think the scope should be NARROWER by eliminating the following:

5. Please rank Rangelands in the following areas ( 1 for excellent, 4 for unsatisfactory):

Article relevance

Article timeliness

Article science

Layout and design

Online functionality

6. Rangelands currently comes out 6 times a year. Do you think the frequency of the journal should change?

Yes___No_. If you think the number of issues should change, how often should Rangelands come out (e.g., 2 times a year, 4 times a year):

7. If placing the journal online would reduce costs, would you be willing to (check all that apply)

online subscribe to an electronic version that is only

_subscribe to a print version and have access to the online

I would not use an electronic version and would be willing to pay the extra to receive a print version

8. Please check the geographic area that best describes your location:
U.S. Northwest
U.S. South
U.S. Southwest
Canada West
U.S. Northeast
U.S. Midwest
Asia-Pacific
Latin America
Canada East
Europe

9. How would you characterize the type of setting in which you work?

University researcher/professor

University student

Nonprofit conservation organization

For-profit company or firm

Federal agency

State/provincial/tribal agency

Other that were frequently mentioned were fire/burning, monitoring, and restoration.

\section{Question 3. Types of Articles Most Interested In}

$$
\text { (\% of } 871 \text { respondents) }
$$

$\begin{array}{ll}\text { How-to } & 92 \\ \text { Research } & 78 \\ \text { Opinions/Editorial/Essays } & 58 \\ \text { Government/Association } & 57\end{array}$

$\begin{array}{ll}\text { Lifestyle } & 57 \\ \text { Multicultural } & 48 \\ \text { SRM News } & 44 \\ \text { Profiles } & 29\end{array}$

\section{Question 4. Scope of Rangelands}

(\% of 871 respondents)

Fine the way it is 85

Should be narrower 15

Should be broader 


\section{Question 5. Rank of Areas of Rangelands}

(Scale-1, excellent; 2, good; 3, fair; 4, poor) Rankings (combining excellent and good).

(\% of 871 respondents who answered "excellent" or "good")

Layout and design 90

Article relevance 89

Article timeliness 87

Article science 82

Online functionality

\section{Question 6. Publication Frequency of Rangelands}

Almost $90 \%$ of the responders would not change the frequency of publication.

\section{Question 7. Publication method of Rangelands}

According to the responses, $58 \%$ of the members prefer access to the journal in both print and online. One-third use the journal online only, and $20 \%$ prefer to continue receiving the printed version only.

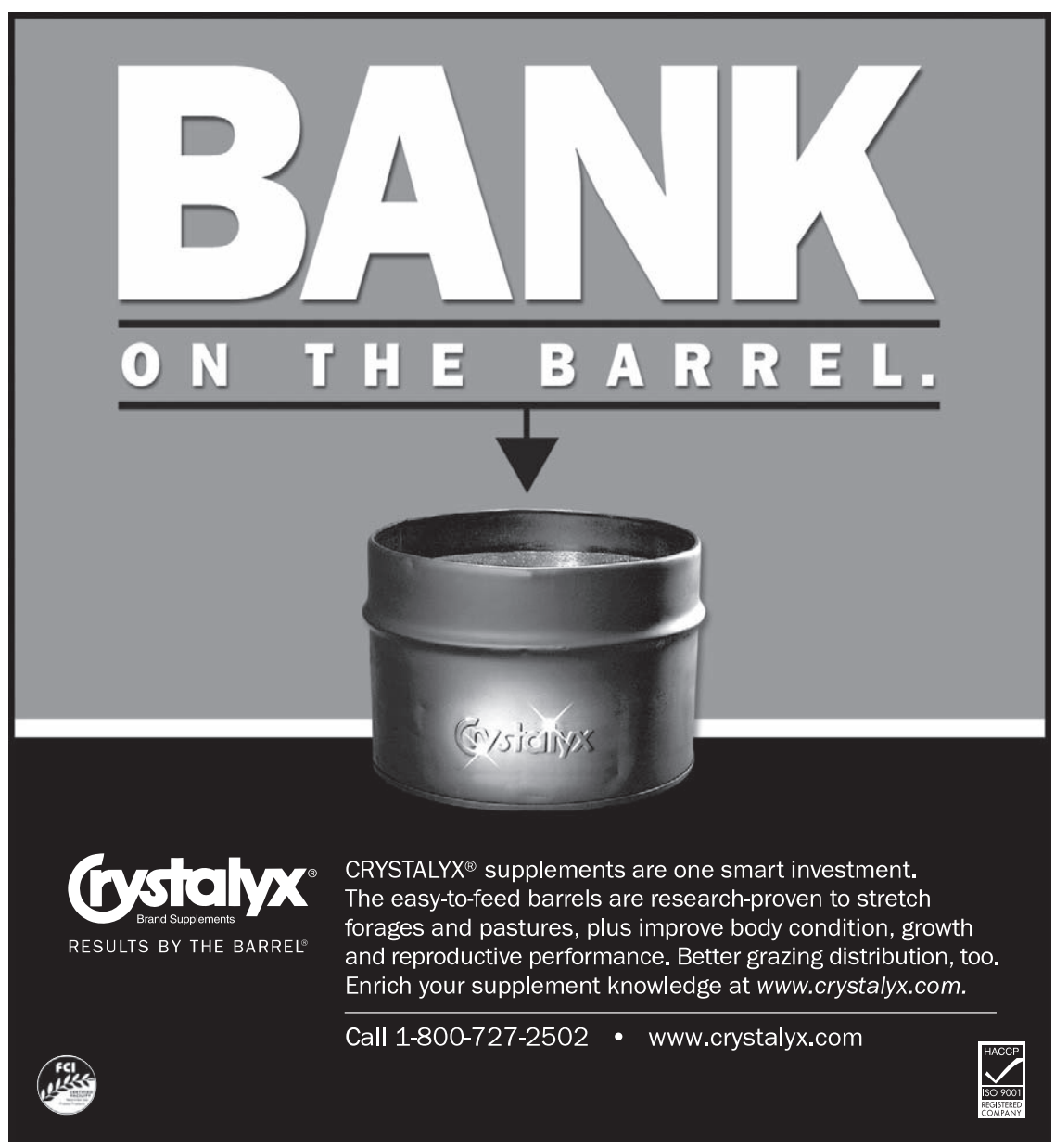

